\title{
Multiplicação in vitro de segmentos apicais caulinares de segurelha (Satureja hortensis L.)
}

NAVROSKI, M.C.I ${ }^{1 *}$; WALDOW, D.A.G. ${ }^{\text {; }}$ REINIGER, L.R.S. ${ }^{1}$; GOLLE, D.P. ${ }^{1}$; CURTI, A.R. ${ }^{1}$; PEREIRA, M.O. ${ }^{1}$ ${ }^{1}$ Universidade Federal de Santa Maria, Departamento de Fitotecnia, Centro de Ciências Rurais. Av. Roraima, 1000. Camobi, CEP: 97105-900. Santa Maria, Rio Grande do Sul. (*) navroskiflorestal@yahoo.com.br

RESUMO: O presente estudo teve por objetivo avaliar o efeito de BAP, na presença e ausência de ANA, sobre a multiplicação in vitro de segmentos apicais caulinares de Satureja hortensis. Os explantes foram isolados de plântulas germinadas in vitro e cultivados em meio nutritivo MS. O delineamento experimental utilizado foi o inteiramente casualizado, em esquema fatorial $2 \times 5$, correspondendo às concentrações de ANA $(0$ e $1 \mu \mathrm{M})$ e de BAP $(0 ; 5 ; 10 ; 15$ e $20 \mu \mathrm{M})$, com seis repetições, cada uma composta por três explantes. Para a porcentagem de explantes com brotações houve efeito significativo para o fator BAP, aumentando à medida que cresce a concentração da citocinina. A variável "número de brotos por explante" apresentou interação entre os fatores, havendo a maior formação de brotos na presença de ANA na faixa de 10 - 15 $\mu \mathrm{M}$ de BAP. Na presença da auxina, o maior valor ocorreu com $15 \mu \mathrm{M}$ de BAP tendendo a diminuir independente da presença de ANA. O enraizamento dos segmentos apicais foi maior na presença de ANA e ausência de BAP, diminuindo com o aumento da citocinina. O número de folhas foi influenciado pela maior concentração de BAP sendo que a $15 \mu \mathrm{M}$ foi observado o maior número, tendendo à queda com aumento da concentração. A concentração de 15 $\mu \mathrm{M}$ de BAP, independente de ANA, proporcionou os melhores resultados na multiplicação da espécie produzindo aumento de brotações e número de folhas, à exceção do enraizamento que foi influenciado pela auxina.

Palavras-chave: cultura de tecidos, regulador de crescimento, plantas medicinais, Lamiaceae.

ABSTRACT: In vitro multiplication of apical shoot segments of Summer Savory(Satureja hortensis L.). This study aimed to evaluate the effect of BAP in the presence and absence of NAA, on the in vitro multiplication of shoot apical segments of Satureja hortensis. The explants were isolated from seedlings germinated in vitro and cultured in nutrient medium MS. The experimental design was completely randomized in a $2 \times 5$ factorial arrangement, corresponding to the concentrations of $\operatorname{NAA}(0$ and $1 \mu \mathrm{M})$ and $\operatorname{BAP}(0,5,10,15$ and $20 \mu \mathrm{M})$, with six replicates, each consisting of three explants. For the percentage of explants with shoots, there was no significant effect for the factor BAP, increasing as the concentration of BAP grows. The variable number of shoots per explant showed interaction between factors, with the highest shoot formation in the presence of NAA and BAP in the range of $10-15 \mu \mathrm{M}$. In the presence of auxin, the highest value occurred with $15 \mu \mathrm{M}$ BAP, tending to decline regardless of the presence of NAA. The rooting of the apical segments was higher in the presence of NAA and absence of BAP, decreasing with increasing cytokinin. Leaf number was influenced by the higher concentration of BAP, and the amount of $15 \mu$ Mhadthe largest number, tending to decrease with increasing concentration. The concentration of $15 \mu \mathrm{M}$ BAP, regardless of NAA, provided better results in the multiplication of the species, producing increased number of shoots and leaves, except for rooting, whichwas influenced by auxin.

Keywords: tissue culture, plant growth regulator, medicinal plants, Lamiaceae

\section{INTRODUÇÃO}

Satureja hortensis L. (Lamiaceae), conhecida como segurelha, é originária do Mediterrâneo Oriental e cultivada em diversas partes do mundo (Sefidkon et al., 2006). É largamente utilizada como tempero, mas de suas folhas e hastes também são extraídos óleos, resinas, 
tinturas e extratos para a indústria de perfumaria (Mihajilov-Krstev et al., 2009). Folhas, flores e caule de Satureja hortensis são utilizados com frequência no preparo de chás ou como aditivo em misturas de especiarias comerciais para alimentos, muitas vezes para oferecer aroma e sabor. Também tem sido usada como planta medicinal para tratar várias doenças, tais como cãibras, dores musculares, náuseas, indigestão, diarreia e doenças infecciosas. Apresenta propriedades antiespasmódicas, antidiarreicas, sedativas, antioxidantes e antimicrobianas (Hajhashemi et al., 2000).

Dentre as formas de propagação de espécies vegetais, a técnica de cultura de tecidos denominada micropropagação é utilizada em larga escala para a produção de plantas dotadas de superioridade bioquímica, genética, fisiológica e sanitária (Grattapaglia \& Machado, 1998).

Entre as vantagens da utilização desta técnica está a possibilidade de se obterem várias plantas a partir de um explante inicial, independente da estação do ano; redução do tempo e da área necessária à propagação da espécie; melhores condições sanitárias; reprodução do genótipo da planta-mãe, com fidelidade durante a multiplicação e propagação vegetativa de espécies difíceis de serem propagadas por outros métodos (Erig \& Schuch, 2005). Outra vantagem é que diversas partes da planta-matriz podem ser utilizadas como fonte de explantes para o estabelecimento in vitro e rápida regeneração das plantas medicinais, como segmentos nodais, ápices caulinares, discos foliares e embriões (Campos et al., 2007).

Apesar do gênero Satureja ser fonte de importantes compostos biologicamente ativos, as informações científicas sobre estas plantas são muito escassas. Desta forma, estudos acerca de métodos adequados de propagação, bem como técnicas de cultivo são importantes na busca de soluções que resultem em maior produção de biomassa, além de garantir a perpetuação da espécie (Diniz et al., 2003).Com relação ao cultivo in vitro do gênero Satureja, poucos estudos foram realizados.

A técnica da micropropagação vem sendo muito utilizada em espécies florestais, frutíferas, ornamentais e agrícolas. A utilização em plantas medicinais pode auxiliar no aumento de metabólitos secundários úteis aos seres vivos de modo que as espécies possam ser mais exploradas economicamente (Rodrigues \& Almeida, 2010).

Considerada a importância medicinal, econômica e a carência de conhecimento acerca da propagação via cultura de tecidos, o presente estudo teve por objetivo avaliar o efeito de 6-Benzilaminopurina - BAP, na presença e na ausência de Ácido alfa-Naftaleno Acético - ANA, sobre a multiplicação in vitro de segmentos apicais caulinares de Satureja hortensis.

\section{MATERIAL E MÉTODOS}

Os explantes utilizados foram provenientes da germinação in vitro de sementes de Satureja hortensis L. em meio de cultura MS (Murashige \& Skoog, 1962), acrescido de $30 \mathrm{~g} \mathrm{~L}^{-1}$ de sacarose, 100 $\mathrm{mg} \mathrm{L}^{-1}$ de mio-inositol e $7 \mathrm{~g} \mathrm{~L}^{-1}$ de ágar. Previamente, as sementes foram desinfestadas superficialmente pela imersão, por 30 segundos em etanol a $70 \%$ $(\mathrm{v} / \mathrm{v})$, por 15 minutos em hipoclorito de sódio $(\mathrm{NaOCl})$ a $1,5 \%(\mathrm{v} / \mathrm{v})$ e, por fim, foram submetidas a um triplo enxágue com água destilada estéril.

Das plântulas obtidas foram isolados os explantes, segmentos apicais caulinares, com aproximadamente $1 \mathrm{~cm}$ de comprimento, os quais foram inoculados em meio nutritivo MS (Murashige \& Skoog, 1962), acrescido de sacarose, mio-inositol e ágar nas mesmas concentrações usadas para a germinação in vitro.

Na germinação e na propagação in vitro o $\mathrm{pH}$ foi ajustado para 5,8, imediatamente antes da esterilização em autoclave, a qual foi efetuada por 20 minutos a $120^{\circ} \mathrm{C}$ e a $1 \mathrm{~atm}$. Frascos com capacidade para $150 \mathrm{~mL}$, contendo $30 \mathrm{~mL}$ de meio nutritivo, foram mantidos em sala de crescimento durante todo o experimento sob temperatura de $25 \pm 2^{\circ} \mathrm{C}$, fotoperíodo de 16 horas, intensidade luminosa de $20 \mathrm{\mu mol}^{-2} \mathrm{~m}^{-2} \mathrm{~s}^{-1}$ obtida por lâmpadas fluorescentes brancas, tipo luz do dia de $20 \mathrm{~W}$ dispostas a uma distância de $25 \mathrm{~cm}$.

O delineamento experimental utilizado foi 0 inteiramente casualizado, em esquema fatorial $2 \mathrm{x}$ 5 , correspondendo às concentrações de ANA (0 e $1 \mu \mathrm{M})$ e de $\operatorname{BAP}(0 ; 5 ; 10 ; 15$ e $20 \mu \mathrm{M})$, totalizando 10 tratamentos com seis repetições, cada uma composta por três explantes. Após 60 dias de cultivo foi avaliada, de forma visual, a porcentagem de explantes com brotações (PEB), número de brotos por explante (NBE), porcentagem de explantes com formação de raízes (PFR) e o número de folhas por explante (NFE).

Após testar a normalidade dos dados pelo teste de Kolmogorov-Smirnov e a homogeneidade de variâncias pelo teste de Bartlett as variáveis foram transformadas para a função $\sqrt{x+0,5}$, sempre que necessário, e submetidas à análise de variância. Quando houve necessidade, realizouse o desdobramento das interações, sendo as médias comparadas pelo teste " $\mathrm{t}$ " de Student e/ ou submetidas à regressão polinomial a $5 \%$ de probabilidade de erro. No caso de efeito significativo de equações quadráticas, determinou-se o ponto de máxima eficiência técnica (MET). O pacote

Rev. Bras. PI. Med., Campinas, v.16, n.1, p.117-121, 2014. 
estatístico Sisvar (Ferreira, 2011) foi utilizado para a análise estatística dos dados.

\section{RESULTADOS E DISCUSSÃO}

Decorridos 60 dias do início do cultivo in vitro dos segmentos apicais caulinares, observouse interação $(p<0,05)$ entre os fatores ANA e BAP para as variáveis NBE e PFR. Para PEB e NFE houve efeito significativo $(p<0,05)$ somente para $o$ fator BAP.

Em relação à porcentagem de explantes que apresentaram brotos (PEB), observou-se comportamento linear positivo para as concentrações de BAP (Figura 1A). Independente da presença ou ausência de ANA houve um aumento na formação de brotos à medida que aumentou a concentração de BAP. Obteve-se um valor próximo à zero na ausência da citocinina, atingindo $75 \%$ quando os explantes foram cultivados na maior concentração $(20 \mu \mathrm{M})$ de BAP testada. Para o número de brotos por explante houve comportamento quadrático na ausência de ANA (Figura 1B). O percentual máximo foi observado a $15 \mu \mathrm{M}$ de BAP e a partir desta concentração observa-se uma tendência de queda do número de brotos com o aumento da citocinina.

A resposta obtida está de acordo com o esperado, uma vez que as citocininas estimulam a maior produção de partes aéreas até uma determinada concentração, o que varia de acordo com a espécie e, a partir desta, ocorre efeito tóxico, que se caracteriza pela redução no número de brotações e falta de alongamento das culturas (Grattapaglia \& Machado, 1998). Neste trabalho, observou-se que a $20 \mu \mathrm{M}$ de BAP houve diminuição no percentual de explantes com brotações, o que sugere que essa concentração de BAP pode ser tóxica para Satureja hortensis.

Alguns estudos realizados com outras espécies da família Lamiaceae revelaram que menores concentrações de BAP que as utilizadas neste trabalho foram suficientes para a formação de brotações. Em Melissa officinalis L. e Mentha piperita L. observou-se que o desenvolvimento de brotos e de segmentos nodais foi maior com $8,8 \mu \mathrm{M}$ de BAP na ausência de ANA (Beduhn, 2005). Em Origanum vulgare $L$., a maior frequência de brotações (85\% dos explantes) foi obtida com a utilização de $8,8 \mu \mathrm{M}$ de BAP e de 0,55 $\mu$ M de ANA (Oana et al., 2008).

Na presença de ANA a formação de brotos por explante apresentou um comportamento quadrático, a exemplo de sua ausência (Figura 1B). A $10 \mu \mathrm{M}$ de BAP foram obtidos cerca de quatro brotos por explante, sendo que o valor da MET foi obtido na concentração de $13 \mu \mathrm{M}$, atingindo 4,08 brotos por explante. $\mathrm{O}$ aumento na concentração desta citocinina para $20 \mu \mathrm{M}$ foi prejudicial para a formação de brotos. Igualmente, em Origanum vulgare L., o uso associado de BAP $(8,8 \mu \mathrm{M})$ e ANA $(0,54 \mu \mathrm{M})$ foi responsável pelo maior número de brotos por explante, atingindo a média de 12,1 (Oana et al., 2008). No mesmo trabalho, o aumento na concentração desses fitorreguladores determinou o decréscimo no número de brotações, sendo que algumas se tornaram necróticas.

O enraizamento dos explantes (PFR) mostrou comportamento quadrático negativo, sendo que o maior valor $(66,7 \%)$ foi obtido na presença de ANA e ausência de BAP (Figura 2A) e, com o aumento da citocinina, houve considerável redução
A

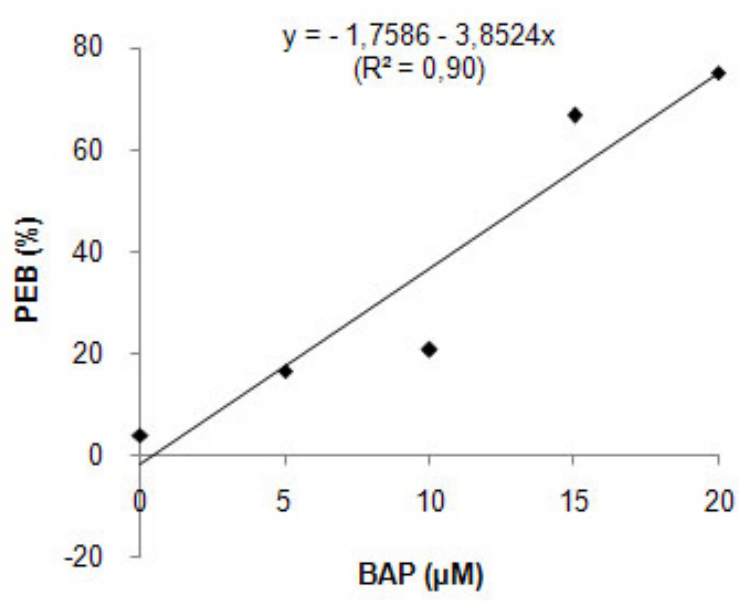

B

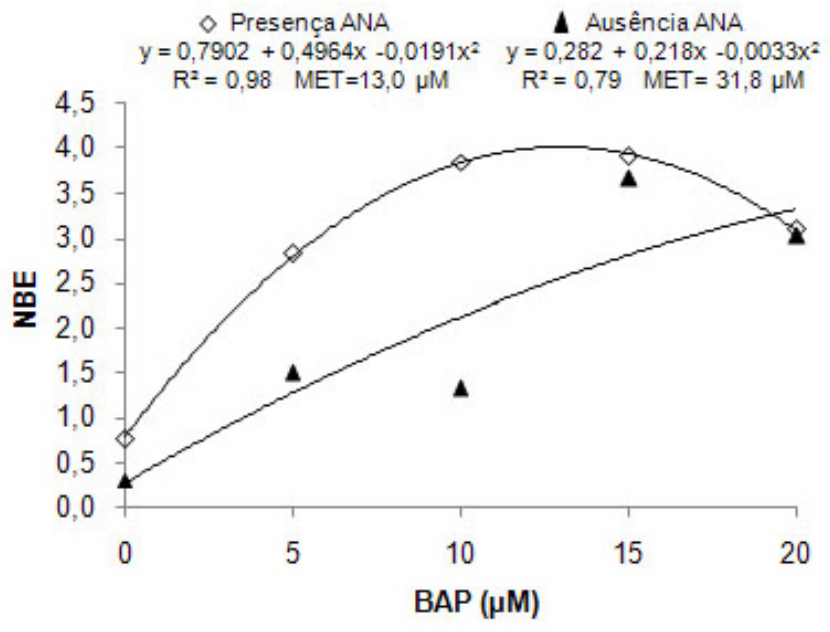

FIGURA 1. A- Porcentagem de explantes com brotações (PEB); B - Número de brotos por explante (NBE) em segmentos apicais caulinares de segurelha (Satureja hortensis L.), aos 60 dias de cultivo in vitro, em meio nutritivo MS.

Rev. Bras. PI. Med., Campinas, v.16, n.1, p.117-121, 2014. 
da rizogênese. Na ausência de ANA não foi obtido ajuste significativo a uma equação de regressão, observando-se reduzido percentual de explantes enraizados. Os resultados encontrados neste trabalho ratificam que concentrações elevadas de citocinina geralmente inibem ou atrasam a formação de raízes e também evitam o crescimento e os efeitos benéficos das auxinas sobre a iniciação radicular (Rout et al., 2006).

Tendência semelhante foi observada na propagação in vitro de Pfaffia glomerata. A maior percentagem de enraizamento foi observada nos brotos cultivados em meio MS não acrescido de citocinina enquanto que na presença de BAP ou TDZ houve uma redução significativa no enraizamento dos brotos (Flores et al., 2009). O efeito inibitório das citocininas na regeneração de raízes é relatado em Lens culinaris Medik (Khawar et al., 2004), Cajanus cajan L. (Eapen et al., 1998) entre outras espécies com propriedades medicinais. Esses efeitos podem ser explicados pelo fato do BAP alterar 0 metabolismo de citocininas naturais, culminado no aumento do teor endógeno das mesmas (Mok et al., 1987).

Com o aumento das concentrações de BAP é possível constatar que houve um aumento no número de folhas até a concentração de 15 $\mu \mathrm{M}$, com ponto de máxima obtido em $15,5 \mu \mathrm{M}$, observando-se um decréscimo para a variável (Figura 2B). Resultados semelhantes foram obtidos em trabalho com Rubus spp. em que observouse redução no número de folhas com o aumento das concentrações de BAP (Villa et al., 2005). Para Dendranthema grandiflora Tzlev, também foi observada uma redução no número de folhas com o aumento das concentrações de BAP. Isso pode ser atribuído ao fato do regulador de crescimento BAP estimular a formação de maior número de brotos, porém, de tamanho reduzido, apresentando menor número de segmentos nodais e, por conseguinte, folhas Oliveira (1994).

$\mathrm{Na}$ multiplicação de espécies medicinais, dependendo da espécie, o maior número de folhas foi obtido na ausência de BAP ou em concentrações baixas da auxina. Em Thymus vulgaris L. o maior número de folhas foi obtido com 2,7 $\mu \mathrm{M}$ de ANA sem a adição de BAP (Rubin et al., 2007). Da mesma forma encontrou-se o maior valor $(64,0)$ na proliferação in vitro de brotos de Lippia alba [(Mill.) N. E. Brown] (Asmar et al., 2012). Em estudo realizado com Ocimum basilicum L., o maior número de folhas por explante foi obtido empregando-se 8,8 e 17,7 $\mu$ M de BAP (24,6 e 20,6 folhas por explante respectivamente) sendo que na presença da maior concentração de BAP testada $(35,5 \mu \mathrm{M})$ as médias diminuíram (Santana et al., 2006).

\section{CONCLUSÃO}

Conclui-se que a porcentagem de explantes com brotações cresceu conforme aumentavam as concentrações de BAP. A concentração de $15 \mu \mathrm{M}$ de BAP possibilita a formação do maior número de brotos e folhas, independente da presença ou ausência de ANA. O maior enraizamento ocorreu na presença de ANA $(1 \mu \mathrm{M})$ e ausência de BAP, evidenciando a importância da presença da auxina no enraizamento.

\section{REFERÊNCIA}

ASMAR, S.A. Concentrações de BAP sobre a proliferação in vitro de brotos de Lippia alba [(Mill.) N. E. Brown].
A

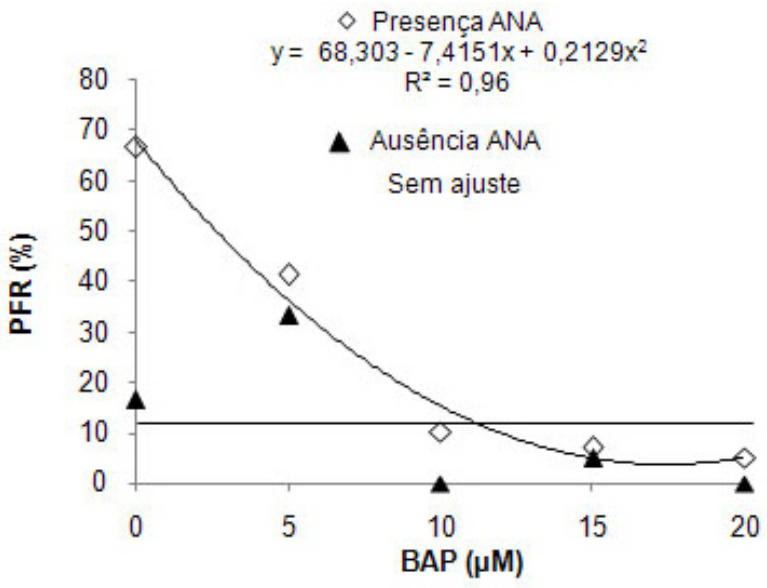

B

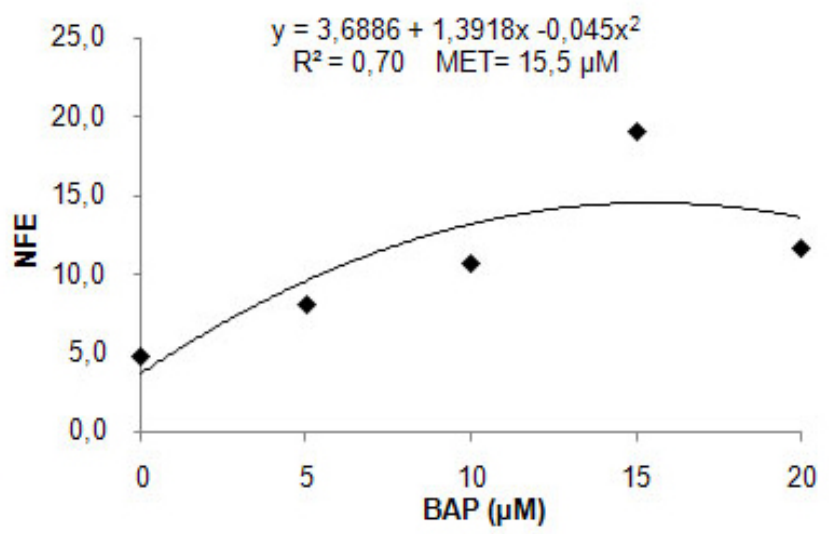

FIGURA 2. A - Porcentagem de explantes com formação de raízes - PFR (\%); B- Número de folhas por explante (NFE) em segmentos apicais caulinares de segurelha (Satureja hortensis L.), aos 60 dias de cultivo in vitro, em meio nutritivo MS.

Rev. Bras. PI. Med., Campinas, v.16, n.1, p.117-121, 2014. 
Revista Brasileira de Plantas Medicinais, v.14, n.esp., p.149-153, 2012.

BEDUHN, F.A. Estabelecimento e propagação in vitro de plantas medicinais da família Lamiaceae. 2005. 58p. Dissertação de Mestrado, Curso de Pós-graduação em Fisiologia Vegetal, Universidade Federal de Pelotas.

CAMPOS, R.A.S. et al. Micropropagação de Jatropha elliptica (Pohl) Müll. Arg. Revista Brasileira de Plantas Medicinais, v.9, n.3, p.30-36, 2007.

DINIZ, J.D.N. et al. Ácido giberélico $\left(\mathbf{G A}_{3}\right)$ e 6 -benzilaminopurina (BAP) no crescimento in vitro de macela [Egletes viscosa (L.) Less.]. Ciência e Agrotecnologia, v.27, n.4, p.934-938, 2003.

EAPEN, S. et al. Thidiazuron induced shoot regeneration in pigeonpea (Cajanus cajan L.). Plant Cell, Tissue and Organ Culture, v.53, n.6, p.217-220, 1998.

ERIG, A.C.; SCHUCH, M.W. Micropropagação fotoautotrófica e uso da luz natural. Ciência Rural, v.35, n.4, p.961-965, 2005

FERREIRA, D.F. Sisvar: a computer statistical analysis system. Ciência e Agrotecnologia (UFLA), v. 35, n.6, p. 1039-1042, 2011.

FLORES, R. et al. Benzilaminopurina (BAP) e thidiazuron (TDZ) na propagação in vitro de Pfaffia glomerata (Spreng.) Pedersen. Revista Brasileira de Plantas Medicinais, v.11, n.3, p. 292-299. 2009.

GRATTAPAGLIA, D.; MACHADO, M.A. Micropropagação. In: TORRES, A.C.; CALDAS, L.S.; BUSO, J.A. Cultura de tecidos e transformação genética de plantas. Brasília: Embrapa SPI / Embrapa CNPH, 1998. v. 1, p. 183260.

HAJHASHEMI, V. et al. Antispasmodic and anti-diarrhoel effect of Satureja hortensis L. essential oil. Journal of Ethnopharmacology, n. 71, v.1, p. 187-192, 2000.

KHAWAR, K.M. et al. Effect of thidiazuron on shoot regeneration from different explants of lentil (Lens culinaris Medik.) via organogenesis. Turk Journal Botany, v.28, p.421-426, 2004.

MIHAJILOV-KRSTEV, T. et al. Composition and antibacterial activity of Satureja hortensis L. essential oil. Central European Journal of Biology. v.4, n.3, p.411-416. 2009.

MOK, M.C. et al. Biological and biochemical effects of cytokinin-active phenylurea derivates in tissue culture systems. HortScience, v.22, n.6, p.1194-7, 1987.

MURASHIGE, T.; SKOOG, F. A revised medium for rapid growth and biossays whit tobacco tissue cultures. Physiological Plant, v.15, p.473-497, 1962.

OANA, C.T. et al. Considerations regarding the effects of growth regulators over the "in vitro" morphogenetic reaction at Origanum vulgare L. Journal of Plant, v.15, p.133-138, 2008.

OLIVEIRA, P. D. Propagação in vitro de crisântemo (Dendranthema grandiflora Tzlev.) cv. Orange Reagen. 1994. 116f. Dissertação (Mestrado em Fitotecnia)-Escola Superior de Agricultura de Lavras, Lavras.

RODRIGUES, F. R.; ALMEIDA, W. A. B. Calogênese em Cissus sicyoides $\mathrm{L}$. a partir de segmentos foliares visando à produção de metabólitos in vitro. Revista brasileira de Plantas Medicinais. v.12, n.3, p.333340. 2010.

ROUT, G. R. A. et al. Tissue culture of ornamental pot plant: a critical review on present scenario and future prospects. Biotechnology Advances, v. 24 , n. 6 , p.531-560, 2006.

RUBIN, S. et al. Reguladores de crescimento na multiplicação in vitro de Thymus vulgaris L. Revista Brasileira de Biociências, v.5, supl.2, p.480-482, 2007.

SANTANA, J. G. S. et al. Influência de concentrações de BAP na micropropagação de manjericão (Ocimum basilicum L. - NSL6421-S2-05). In: Congresso Brasileiro de Olericultura, 46., 2006, Goiânia GO. Anais... Goiás: Associação Brasileira de Horticultura, Universidade Federal de Goiás, Embrapa Hortaliças, 2006.

SEFIDKON, F. et al. Influence of drying and extraction methods on yield and chemical composition of the essential oil of Satureja hortensis. Food Chemistry, v.99: p.19-23. 2006.

VILLA, F. et al. Multiplicação in vitro da amoreira-preta 'Ébano' em diferentes concentrações de meio MS e BAP. Ciência e Agrotecnologia, v.29, n.3, p.582-589, 2005. 